\title{
Chronic expanding hematoma of the thorax
}

\author{
Charles L. Roper, MD, and Joel D. Cooper, MD, St Louis, Mo
}

$\mathrm{T}$

he surgical literature is replete with case reports of chronic expanding hematomas, that is, ancient hematomas, involving almost every organ system; however, a paucity of information exists concerning this entity arising from the thorax except for that found in several Japanese reports. ${ }^{1}$ In a majority of these cases, a remote surgical procedure for tuberculosis seemed to be the initiating factor. As with all chronic expending hematomas, symptoms may arise months or years after trauma or surgery. When first noted, these lesions frequently are thought to represent soft tissue sarcomas or other malignant tumors. ${ }^{2}$ Characteristic of this entity is the fact that our patient had a latent period of 30 years before the onset of symptoms.

\section{Clinical Summary}

A 57-year-old white man had undergone a right lower lobectomy followed by a completion pneumonectomy for tuberculosis 30 years earlier. After a brief recuperative period, he had returned to a physically demanding occupation that he pursued until 1 year before admission for increasing shortness of breath in 1998. In 1986, the patient had angina and underwent a balloon angioplasty.

A chest radiograph taken in 1987 (Figure 1) revealed an opacified right pleural space with a mediastinal shift to the operative side, as would be anticipated after a right pneumonectomy. Another film taken in 1994 (Figure 2) revealed that the mediastinum had shifted somewhat back toward the midline, but the patient remained free of symptoms. Although the patient had noticed increasing dyspnea during the prior year, an acute exacerbation resulted in his being sent to the Washington University Lung Center in August 1998. A repeat radiologic examination, which included computed axial tomography, revealed a midline mediastinum with compression of the left stem bronchus, a long right bronchial stump, and an opaque right pleural space outlined by irregular masses of calcifications (Figure 3). The previously noted long right stem bronchial stump and marked extrinsic compression of the left stem bronchus were observed via a fiberoptic bronchoscope (Figure 4).

\footnotetext{
From the Division of Cardiothoracic Surgery, Department of Surgery, Washington University School of Medicine, St Louis, Mo.

Received for publication April 23, 2001; accepted for publication May 2, 2001.

Address for reprints: Joel D. Cooper, MD, Suite 3108 Queeny Tower, One Barnes-Jewish Hospital Plaza, St Louis, MO 63110 (E-mail: cooperjo@ msnotes.wustl.edu).

J Thorac Cardiovasc Surg 2001;122:1046-8

Copyright (C) 2001 by The American Association for Thoracic Surgery

$0022-5223 / 2001 \$ 35.00+0 \quad \mathbf{1 2 / 5 4 / 1 1 7 6 1 7}$

doi: $10.1067 / \mathrm{mtc} .2001 .117617$
}

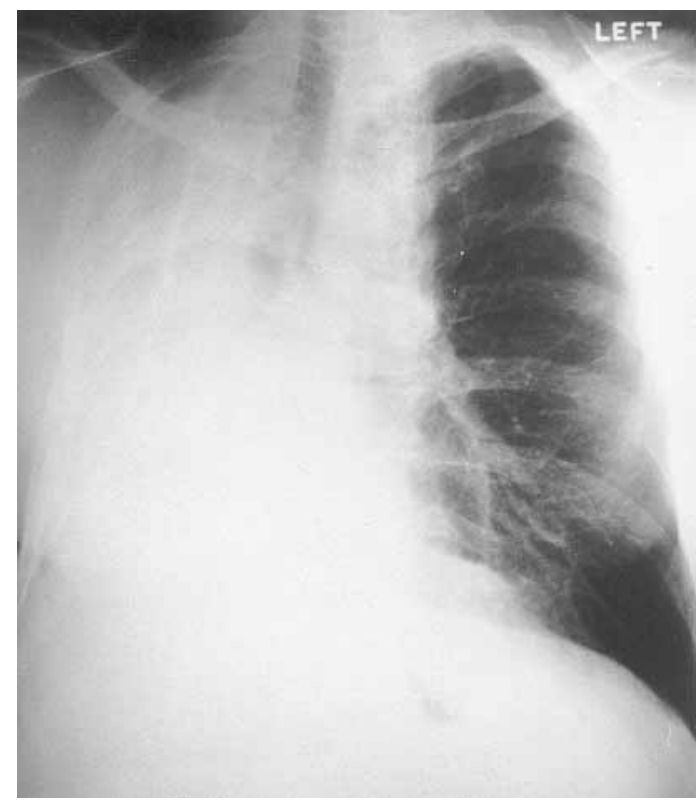

Figure 1. A chest radiograph taken in 1987 reveals findings that one would anticipate after a right pneumonectomy.

Thoracentesis yielded $500 \mathrm{~mL}$ of chocolate-brown fluid that was submitted for stains and cultures for routine organisms, fungi, and Mycobacterium tuberculosis. All results of these studies were reported as being negative. The fluid microscopically contained a predominance of erythrocytes. The patient's symptoms persisted, and 4 days later repeat thoracentesis yielded $800 \mathrm{~mL}$ of the same type of fluid that had been previously aspirated. This procedure gave the patient symptomatic relief, and examination with a bronchoscope now revealed a normal appearing left stem bronchus. However, dyspnea recurred after 2 weeks and, with all cultures showing no growth of any organisms, the patient was then admitted for a definitive procedure. Examination with a fiberoptic bronchoscope again disclosed marked left stem bronchial compression, and thoracoscopy was undertaken. At that time $2500 \mathrm{~mL}$ of darkbrown fluid was removed from the right hemithorax, which was encompassed by a dense fibrinous capsule. Within the capsule large masses of necrotic debris covered areas of irregular calcification, which were interspersed with smooth, highly vascular granulation tissue. Specimens were taken for biopsy from multiple areas within the capsule. The residual pleural space was then irrigated and filled with solution containing kanamycin sulfate. On completion of thoracoscopy, the left stem bronchus was widely patent and the carina and trachea were in the midline. 


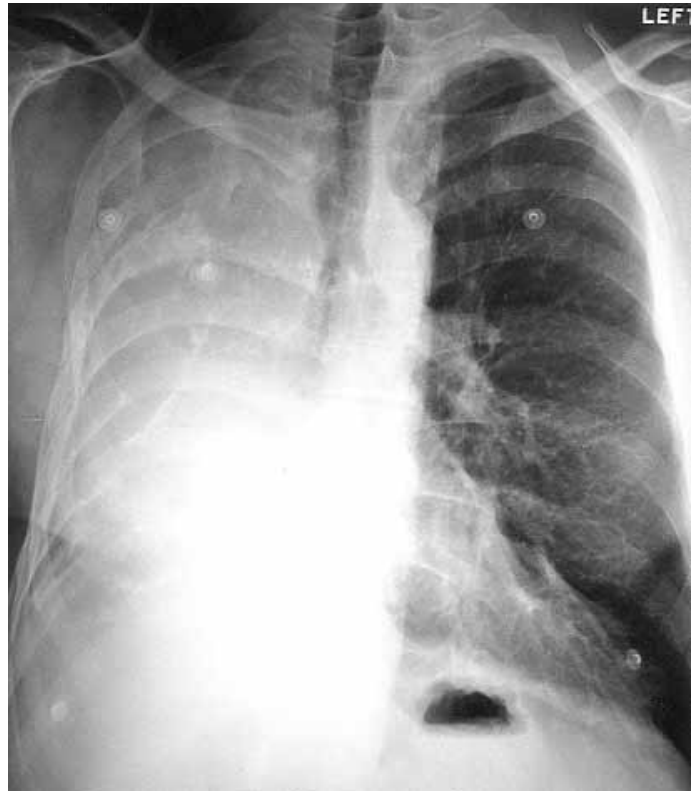

Figure 2. A chest radiograph taken in 1994 reveals that the mediastinum has shifted somewhat back toward the midline, but the patient remained asymptomatic.

Since his discharge, the patient has been closely followed up for $2 \frac{1}{2}$ years and has continued to do well. Computed assisted tomography performed 1 year after the thoracoscopy and a chest radiograph taken $2 \frac{1}{2}$ years after the procedure show only those findings again characteristic of a previous right pneumonectomy, similar to the findings noted in 1987.

\section{Discussion}

Subdural hematoma has been the most widely reported example of expanding hematoma, and most laboratory investigations have focused on this particular entity.

Two widely held hypotheses have arisen to explain the pathogenesis of these lesions. Gardner, ${ }^{3}$ Monroe and Merritt, ${ }^{4}$ and others have postulated a breakdown of blood products, which results in an increased osmolality within the lesion and leads to its expansion. Very little data supported these deductions, and Weir, ${ }^{5}$ in a series of experiments, found no evidence that an increased osmolality occurred within the capsule of the hematoma, thus negating this concept of pathogenesis. A spun down specimen of pleural fluid from our patient had an osmolality of $295 \mathrm{mOsm}$, which was well within the normal limits.

Watanabe, Shimada, and Ishii ${ }^{6}$ were among the first to demonstrate experimentally a volume increase in hematomas. The wellconceived experiments of Labadie and Glover ${ }^{7}$ graphically demonstrated that breakdown products of leukocytes, erythrocytes, hemoglobin, platelets, and fibrin result in an inflammatory process that effectively damages the capillaries of the capsule, thus giving rise to increased fluid production.

Despite the significant calcification in the capsule wall of the hematoma, enough elasticity exists for hematomas to increase in volume over time. With highly vascular granulation tissue inter-

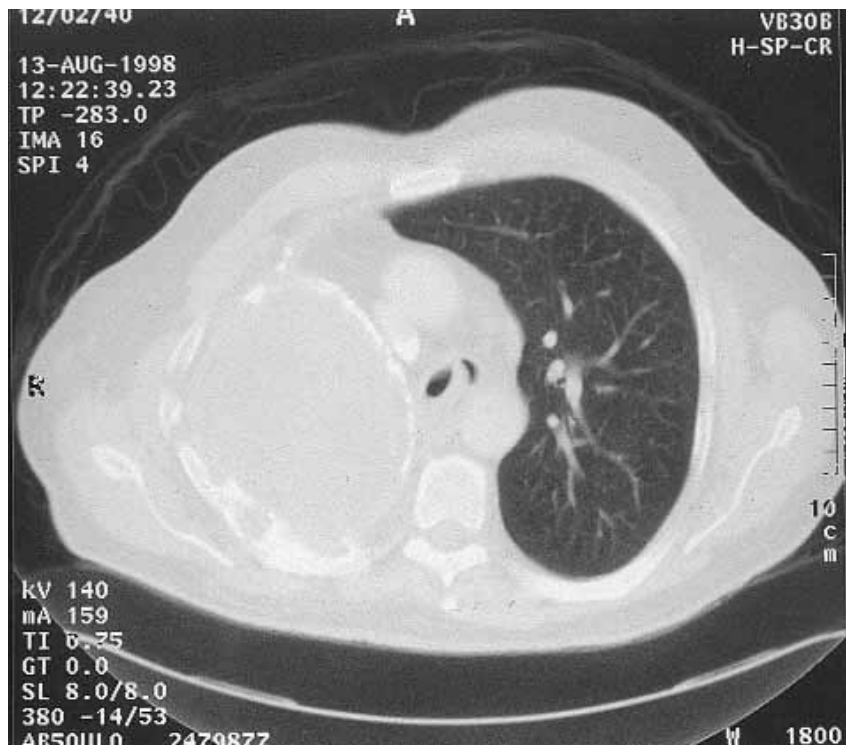

Figure 3. Computed axial tomographic scan revealing the opacified and calcified right pleural space with compression of the left stem bronchus and a long right stem bronchus.

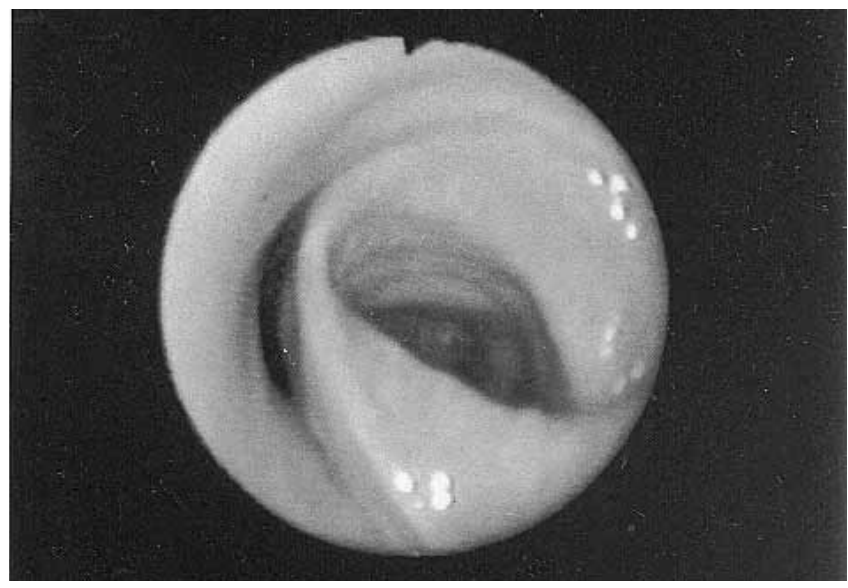

Figure 4. Endoscopic findings showing the carina and confirming the presence of a long right bronchial stump and marked compression of the left stem bronchus.

posed between large, sharp, calcified masses, one could postulate that any severe coughing episode might well give rise to intermittent bleeding at the calcium-granulation tissue interface. Thus, intermittent episodes of bleeding may allow a slow progressive increase in the volume of the hematoma without the need to consider the irritant factor of blood.

Although most reports of expanding hematomas suggest radical excision of the capsule as the treatment of choice, we did not subscribe to this method for our patient. When confronted with a postpneumonectomy space of 30 years' duration, we did not think 
the possible complications and increased morbidity of attempting total capsule excision justified such a procedure, inasmuch as a modification of the second stage of the well-established Clagett procedure would suffice.

\section{References}

1. Hanagiri T, Muranaka H, Hashimoto M, Nishio T, Sakai S, Ono M, et al. Chronic expanding hematoma in the chest. Ann Thorac Surg. 1997; 64:559-61.

2. Mentzel T, Goodlad JR, Smith MA, Fletcher CDM. Ancient hematoma: a unifying concept for a post-traumatic lesion mimicking an aggressive soft tissue neoplasm. Mod Pathol. 1997;10:334-40.
3. Gardner WJ. Traumatic subdural hematoma with particular reference to the latent interval. Arch Neurol Psychiatr. 1932;27:847-58.

4. Munro D, Merritt HH. Surgical pathology of subdural hematoma based on a study of 105 cases. Arch Neurol Psychiatr. 1936;35:64-79.

5. Weir B. The osmolality of subdural hematoma fluid. J Neurosurg. 1971;34:528-33.

6. Watanabe S, Shimada H, Ishii S. Production of clinical form of chronic subdural hematoma in experimental animals. J Neurosurg. 1972; 37:552-61.

7. Labadie EL, Glover D. Physiopathogenesis of subdural hematomas. $J$ Neurosurg. 1976;45:382-92.

8. Duarte IC, Chang HJ, Kennedy JC, Miller JI Jr. Papillary endothelial hyperplasia presenting as a chest wall neoplasm. Ann Thorac Surg. 1999;67:238-40.

\section{JTCVS On-Line Manuscript Submission and Review}

\section{Please visit http://www.editorialmanager.com/jtcvs/}

Effective September 15, 2001, authors and reviewers may submit manuscripts and reviews electronically via Editorial Manager, our new Web-based system with full electronic submission, review, and status update capabilities.

As we move from paper to electronic submissions, the Editorial Office will make proxy submissions of all manuscripts accompanied by a diskette containing the electronic files of the text, tables, and figures. Editors, authors, and reviewers will receive automatic e-mails when significant events occur.

We strongly encourage all authors and reviewers to use Editorial Manager. Although we will continue to accommodate the submission of paper manuscripts for some months, our goal is to be completely electronic within 9 to 12 months.

All individuals currently in our database for whom we have e-mail addresses will receive via e-mail a system-assigned username and password that can be used to log in to the system without prior registration. All those not receiving the e-mail must register the first time they use the system.

As with any broad systemic change, the conversion to the new system will take some time to complete. We ask your patience as we replace our in-office database with the new system. We also encourage you to take advantage of the speed and efficiency that the new system will provide for us all: editor, author, reviewer, and publisher. 